\title{
How does stress exert its effects - smoking, diet and obesity, physical activity?
}

\author{
M. Kornitzer and F. Kittel
}

Laboratoire d'Epidemiologie et de Médecine Sociale, Ecole de Santé Publique, Campus Erasme, Route de Lennik, 808, 1070 Bruxelles, Belgium

\begin{abstract}
Summary: Using a job stress questionnaire a negative correlation was found between job stress and physical fitness and a positive one with Type $A$ behaviour. No correlation was found between job stress and obesity, nutritional patterns or physical activity. Subjects with angina had higher scores on the job stress questionnaire than normal controls. The job stress score was not predictive of future coronary heart disease.
\end{abstract}

A job stress questionnaire was used to assess the degree of stress encountered at work in two cohorts of Belgian white collar workers and executives who were followed for 10 years, starting in 1965 . One cohort came from a private and the other from a largely public bank. A significantly higher incidence of coronary heart disease (CHD) was found in the private bank and could not be explained on the basis of other coronary risk factors (Kittel et al., 1980).

A further job stress questionnaire was then constructed to determine the relation of physical fitness and leisure time activity with CHD (Sobolski et al., 1981). This questionnaire included factors such as aggressive relationships at work, competitive relationships, financial problems, lack of promotion, changes in working conditions, professional mobility and psychosomatic complaints. Seventy four per cent of 3,179 middle aged males attended for examination. No relation was observed between job stress score and age but there was a positive correlation with social class and educational levels. No relation was observed with heart rate, blood pressure, serum cholesterol, HDL cholesterol, triglycerides and body mass index. Smokers had the lowest job stress score followed by nonsmokers and then ex-smokers, the differences being statistically significant (Kornitzer et al., 1980). Subjects with the highest physical fitness had the lowest job stress score. No relation was found between leisure activity and job stress score. Users of tranquillizers had by far the highest job stress score.

A further study (The Belgian Inter-University Research on Nutrition and Health) has just been completed and over 13,000 Belgian citizens have, been screened. The relation of stress to diet was considered by comparing the job stress score with the polyun-

Correspondence: M. Kornitzer, M.D. saturated and saturated fat intake (PS ratio) but no clear pattern emerged. Likewise no relation was found between job stress score and fibre intake. These findings were confirmed by multivariate analysis.

Holter monitoring was carried out in 122 normal subjects and 58 with abnormal electrocardiograms, but no relation was found between job stress score and the frequency of premature beats (Sobolski et al., 1981). The correlation between job stress score and Type A behaviour assessed by means of the Jenkins Activity Survey was determined in each social class, the highest being observed in blue collar workers (Kornitzer et al., 1980).

When professional status and study level are included they are significantly and independently correlated with the job stress score together with smoking habits, quartiles of total leisure time activity (positive correlation!) and finally the work-load on the bicycle ergometer enters as last significant correlate of the job stress score (inverse correlation). A significant positive association of job stress score with angina was found but not with abnormal electrocardiogram. However, in a case control study no differences were found in job stress score between normal controls and new cases of CHD (Kornitzer et al., 1982).

\section{Discussion}

Deanfield et al. (1984) found that stress brought on by mental activity was associated with the appearance of myocardial ischaemia in subjects with CHD. Lown $e t$ al. (1978) found that stressful interviews were associated with the appearance of ventricular premature beats and other more lethal arrhythmias in subjects with CHD. Increased catecholamine levels appeared to decrease the threshold of ventricular

(C) The Fellowship of Postgraduate Medicine, 1986 
fibrillation in animal experiments (Lown et al., 1978). Ruberman et al. (1976) found that those subjects with CHD who had ventricular premature beats were more liable to sudden death. These findings suggest that increased catecholamine levels can produce lethal arrhythmias in subjects with CHD. To confirm these findings a prospective epidemiological study should be carried out in which base line catecholamine levels of blood or urine are estimated to see whether they can act as predictors of further CHD events in patients who have survived a myocardial infarct.

\section{References}

DEANFIELD, J.E., SHEA, M., KENSETT, M., HORLOCK, P., WILSON, R.A., DE LANDSHEERE, C.M. \& SELWYN, A.P. (1984). Silent myocardial ischaemia due to mental stress. Lancet, 3, 1001.

KITTEL, F., KORNITZER, M. \& DRAMAIX, M. (1980). Coronary heart disease and job stress in two cohorts of bank clerks. Psychotherapy and Psychosomatics, 34, 110.

KORNITZER, M., KITTEL, F. DE BACKER, G., DRAMAIX, M., SOBOLSKI, J. \& DEGRE, S. (1980). Work load and coronary heart disease. In Myocardial Infarction and Psychosocial Risks, Siegrist, J. \& Halhuber, M.J. (eds). p. 18. SpringerVerlag: Berlin, Heidelberg, New York.

KORNITZER, M., KITTEL, F., DRAMAIX, M. \& DE BACKER, G. (1982). Job stress and coronary heart disease. Advances in Cardiology, 29, 56.

\section{Conclusions}

With the exception of Type A behaviour and an inverse relation with physical fitness no correlations were observed between job stress score and most of the coronary risk factors examined. The job stress score did not predict new CHD events. It is considered that job stress is likely to be a predictor for recurrence of CHD in those already afflicted.

LOWN, B., KITTEL, F., DRAMAIX, M. \& DE BACKER, G. (1978). Roles of psychologic stress and autonomic nervous system changes in provocation of ventricular premature complexes. American Journal of Cardiology, 41, 979.

RUBERMAN, W., WEINBLATT, E., FRANK, C.W., GOLDBERG, J.D., SHAPIRO, S. \& FELDMAN, C.L. (1976). Prognostic value of one hour of ECG monitoring of men with coronary heart disease. Journal of Chronic Diseases, 29, 497.

SOBOLSKI, J., DE BACKER, G., DEGRE, S., KORNITZER, M. \& DENOLIN, H. (1981). Physical activity, physical fitness and cardiovascular diseases: design of a prospective epidemiologic study. Cardiology, 67, 38. 